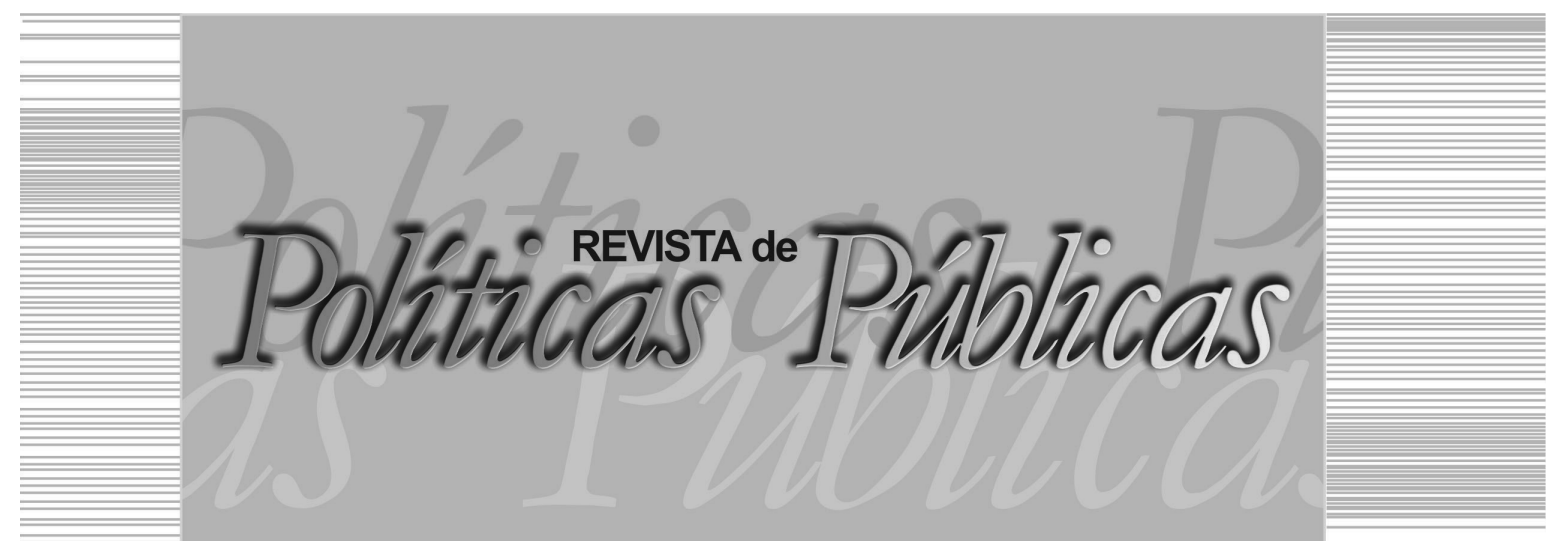

\title{
CONTINGENCIAMENTO ORÇAMENTÁRIO E AUTONOMIA NAS AGÊNCIAS REGULADORAS: o caso da Agência Nacional de Telecomunicações
}

\author{
André Nunes ${ }^{1}$ \\ Universidade de Brasília (UnB) \\ Ministério do Planejamento, Desenvolvimento e Gestão
}

Evandro Luiz Diefenbach ${ }^{2}$ Agência Nacional de Telecomunicações (ANATEL)

Marco Antônio Santana Gomes ${ }^{3}$ Agência Nacional de Telecomunicações (ANATEL)

Kalina Maria Donato de Araujo ${ }^{4}$ Exército Brasileiro

\footnotetext{
Economista, Doutor em Economia pela Universidade de Brasília (UnB), Professor Adjunto da UnB e Diretor de Orçamento de Empresas Estatais, na Secretaria de Empresas Estatais do Ministério do Planejamento, Desenvolvimento e Gestão. E-mail: andrenunes@unb. br / Universidade de Brasília - UnB: Campus Universitário Darcy Ribeiro, Brasília-DF. CEP 70910-900 / Ministério do Planejamento, Desenvolvimento e Gestão: Esplanada dos Ministérios, Bloco K, Brasília, DF. CEP: 70.040-906

2 Administrador de Empresas, Mestrando em Gestão Pública pela UnB, Coordenador de Serviços na Gerência de Infraestrutura, Serviços e Segurança Institucional da Agência Nacional de Telecomunicações (ANATEL). E-mail: diefenba@gmail.com / Agência Nacional de Telecomunicações - ANATEL: Setor de Autarquias Sul, Quadra 6, Bloco H, Asa Sul, Brasília, DF. CEP: 70070940

3 Economista, Mestrando em Gestão Pública pela UnB, Especialista em Regulação de Serviços Públicos de Telecomunicações da ANATEL.E-mail: masgomes@live.com

4 Administradora, Mestranda em Gestão Pública pela Universidade de Brasília (UnB), Administradora no Departamento de Engenharia e Construção do Exército Brasileiro. E-mail: kalinadonato@yahoo.com.br / Exército Brasileiro: SMU, QGEx, Bloco B, $3^{\circ}$ andar, Brasília, DF. CEP: 70630-901
} 
André Nunes | Evandro Luiz Diefenbach $\mid$ Marco Antônio Santana Gomes

Kalina Maria Donato de Araujo

\title{
Resumo
}

As agências reguladoras surgiram no Brasil como autarquias especiais dotadas por lei de autonomia administrativa, financeira e de gestão. Possuem a peculiaridade de ter fontes de arrecadação própria vinculadas à manutenção de suas atividades. Entretanto, na prática, a Agência Nacional de Telecomunicações (Anatel) tem sua proposta orçamentária alterada pelo ministério ao qual se vincula sem hierarquia, desconsiderando-se os normativos, o Princípio do Equilíbrio e recomendações dos Tribunais Superiores. Conclui-se que uma das possíveis causas para isso seja a necessidade de realocar os fundos de infraestrutura para gerar superávit primário ou reduzir o déficit.

Palavras-chave: Agências reguladoras, autonomia financeira e orçamentária, contingenciamento.

\section{BUDGET CUT AND THE AUTONOMY OF THE}

REGULATORY AGENCIES: the National Telecommunications Agency case

\begin{abstract}
The regulatory agencies have emerged in Brazil as special authorities endowed by law of administrative, financial and management autonomy. Have the peculiarity of having sources of revenues linked itself to the maintenance of its activities. However, in practice, the National Telecommunication Agency (Anatel) has its budget proposal amended by the Ministry to which to bind without hierarchy, disregarding the normative, the Principle of Balance and recommendations of superior courts. It is concluded that one of the possible causes for this is the need to reallocate funds from infrastructure to generate a primary surplus or reduce the deficit.

Key words: Regulatory agencies, financial and budgetary autonomy, contingency.

\section{INTRODUÇÃO}

No contexto da reforma do Estado, ocorrida na década de 1990, o Brasil decidiu romper com monopólios estatais e reduzir barreiras à entrada ao capital privado nacional e estrangeiro em setores em que a Administração Pública atuava diretamente, como telecomunicações e energia elétrica. $\mathrm{O}$ objetivo era atrair investidores dispostos a explorar atividades que outrora eram executadas exclusivamente pelo Estado, transformando, assim, o status de atuação do Estado brasileiro de empresário para regulador. O modelo de regulação adotado foi o de agências organizadas como autarquias em regime especial. Tais entidades foram criadas por lei específica,
\end{abstract}


CONTINGENCIAMENTO ORÇAMENTÁRIO E AUTONOMIA NAS AGÊNCIAS

REGULADORAS: o caso da Agência Nacional de Telecomunicações

dotadas de autonomia administrativa, normativa, financeira e orçamentária. As agências foram vinculadas a um ministério, todavia, sem subordinação hierárquica a ele. Essas organizações fazem parte da administração indireta do Poder Executivo Federal e representam a presença do Estado nos setores monopolísticos privatizados, tendo como objetivo fundamental regular e fiscalizar tais setores.

Ao longo da primeira década de 2000 , indícios apontam para a redução da autonomia das agências reguladoras e outras entidades autárquicas que possuem receitas próprias, especialmente no que tange aos aspectos orçamentário e financeiro. O contingenciamento do orçamento das agências e outras interferências de ordem orçamentária e financeira reforçam a sensação de uma gradual redução da autonomia das autarquias especiais destinadas à regulação de serviços públicos.

A autonomia constitui a essência dessas entidades. Definida a partir de instrumentos jurídicos, somente se consagra se a autarquia detiver meios e instrumentos para bem exercer suas funções. Nesse sentido, apesar da autonomia contemplar todos os interesses relacionados à atividade desenvolvida pela entidade, é perante a Administração Central que o seu exercício se mostra mais polêmico.

O presente trabalho tem como objetivo investigar se o contingenciamento orçamentário e financeiro afeta a autonomia da Agência Nacional de Telecomunicações (ANATEL). Para atingir esse objetivo o trabalho foi dividido em cinco partes, sendo a primeira essa introdução. A segunda seção discute o contexto brasileiro em que surgiram as agências reguladoras. A terceira discorre sobre o orçamento público nas agências reguladoras e a autonomia das agências reguladoras. Na quarta, são analisados o orçamento na ANATEL, o planejamento e o processo orçamentário, as receitas próprias e o contingenciamento. Na quinta seção apresentam-se as considerações finais que apontam para a necessidade de urgente readequação na atual forma de contingenciamento do orçamento das agências, sob pena de fazer desaparecer as razões de conveniência que originaram a instituição de agências com autonomia administrativa, normativa, financeira e orçamentária. 
André Nunes | Evandro Luiz Diefenbach $\mid$ Marco Antônio Santana Gomes Kalina Maria Donato de Araujo

\section{AS AGÊNCIAS REGULADORAS NO CONTEXTO BRASILEIRO}

A existência de órgãos autônomos, dentro da estrutura administrativa dos governos, não é fato recente. Desde 1834 já existiam entes autônomos na Inglaterra criados pelo Parlamento Inglês para concretizar a aplicação de medidas previstas em leis e decidir controvérsias quanto a sua interpretação. Sob influência inglesa, a partir de 1887, tem início nos Estados Unidos a proliferação de agencies para regulação de atividades, imposição de deveres na matéria e aplicação de sanções. Embora sem personalidade jurídica e sujeitas à fiscalização do Conselho do Estado, surgiram também na França Autoridades Administrativas Independentes com o propósito de neutralidade política. (GROTTI, 2006).

No Brasil, a ideia de regulação não é assunto estranho nem recente. Segundo Cuéllar (2001) não se pode olvidar que os exemplos do Banco Central do Brasil (BACEN) e do Conselho Administrativo de Defesa Econômica (CADE), já exerciam atividades de natureza regulatória sob a forma de autarquias desde a década de 1960. Mais antigas ainda, segundo Ferreira Filho (2001), são entidades como o Comissariado de Alimentação Pública (1918), o Instituto de Defesa Permanente do Café (IBC, 1923), o Instituto do Álcool e do Açúcar (IAA, 1933), o Instituto Nacional do Mate (INM, 1938), o Instituto Nacional do Sal (INS, 1940), e o Instituto Nacional do Pinho (INP, 1941).

Todavia, a criação das autarquias em regime especial no Brasil emana da Constituição Federal (CF) de 1988, principalmente de seus artigos $173^{\circ}$ e $174^{\circ}$, que, respectivamente, consagram o princípio da subsidiariedade e dispõem acerca da intervenção indireta do Estado na economia. A atuação do Estado brasileiro, até esse período, era tida como direta, focada na produção de alguns bens considerados estratégicos e na prestação de serviços públicos. (MISSE, 2010).

Mas, o formato de agência reguladora autônoma somente tomou corpo na década de 1990 quando o Estado Brasileiro passou por uma reforma administrativa, influenciada pela corrente de pensamento do New Public Management (NPM), o qual rompeu com alguns monopódios estatais visando incentivar a entrada de investimento privado nacional e estrangeiro em setores como petróleo, 
CONTINGENCIAMENTO ORÇAMENTARIO E AUTONOMIA NAS AGÊNCIAS

REGULADORAS: o caso da Agência Nacional de Telecomunicações

energia e telecomunicações, nos quais atuava diretamente. (MISSE, 2010)

Por meio das chamadas emendas liberalizantes a Constituição Federal de 1988 foi alterada nesse período, para, em síntese, promover a extinção de determinadas restrições ao capital estrangeiro (Emendas Constitucionais no 6 e $\mathrm{n}^{\circ}$ 7, de 15 de agosto de 1995) e a atenuação dos monopólios estatais (Emendas Constitucionais $\mathrm{n}^{\mathrm{o}}$ 5 e $^{\circ} 8$ de 15 de agosto de 1995, e ${ }^{\circ} 9$, de 9 de novembro de 1995). Também foi instituído o Programa Nacional de Desestatização (PND), pela Lei n ${ }^{\circ} 8.031$, de 12 de abril de 1990, posteriormente revogada pela Lei oㅗ 9.491, de 9 de setembro de 1997. (SANTOS, 2015)

Essa nova forma de intervenção do Estado na economia trouxe uma nova forma de relacionamento entre o Estado e operadores privados de serviços públicos e também novos mecanismos para sedimentar as bases para a convivência de interesses contrapostos: o Governo, visando disseminar e ampliar serviços; os usuários, demandando serviços de qualidade a preços módicos; e o agente privado, buscando maximizar o retorno de seus investimentos.

Afirma Santos (2015) que o modelo de agência brasileiro nasceu inspirado no modelo norte-americano, embora em contextos e com objetivos distintos: enquanto nos Estados Unidos a maioria das agências foram criadas a partir de 1930 no New Deal em resposta à crise de 1929 com intuito de conferir maior intervenção estatal na economia, já no Brasil foi na década de 1990 e buscava-se reduzir o tamanho do Estado, não para a adoção de uma modelo liberal clássico, mas para fazer com que o Estado atuasse de forma indireta na fiscalização dos particulares prestadores dos serviços públicos concedidos.

Não há, no entanto, uma lei única que defina o que seja uma agência reguladora no Brasil. Isso leva a uma certa confusão quanto ao seu exato significado, dadas as diversas acepções assumidas entre nós pelo vocábulo agência. Contudo, essa autora aponta que no nosso sistema, as agências reguladoras destinam-se precipuamente a regular serviços públicos cuja execução passou a ser prestada por particulares anotando ser imperioso reiterar que a função desempenhada por agências reguladoras pode ter por objeto outras atividades econômicas tal como ocorre nos Estados Unidos e na França. (CUÉLLAR, 2001). 
André Nunes | Evandro Luiz Diefenbach $\mid$ Marco Antônio Santana Gomes

Kalina Maria Donato de Araujo

Com base em sua concepção administrativista do direito, Cuéllar (2001, p. 77) oferece um conceito de agência ao afirmar que "[...] são pessoas jurídicas de Direito Público, com estrutura formal autárquica e competência para regulamentar, contratar, fiscalizar, aplicar sanções e atender aos reclamos dos usuários/consumidores de determinado serviço público ou atividade econômica."

Para Di Pietro (2007) em sentido amplo, no direito brasileiro, agência reguladora é qualquer órgão da Administração Direta ou entidade da Administração Indireta com função de regular a matéria específica que lhe está afeta.

Sobre a função de regular, a própria CF de 1988 já previa em seu art. $174^{\circ}$ que: "Como agente normativo e regulador da atividade econômica, o Estado exercerá, na forma da lei, as funções de fiscalização, incentivo e planejamento, sendo este determinante para o setor público e indicativo para o setor privado." (BRASIL, 1988)

Moreira Neto (2003) explica que a função reguladora comporta um híbrido de atribuições de variada natureza: informativas, planejadoras, fiscalizadoras e negociadoras, mas, também, normativas, ordinatórias, gerenciais, arbitradoras e sancionadoras. Já para Barroso (2005), embora a etimologia sugira a associação da função reguladora com o desempenho de competências normativas, seu conteúdo é mais amplo e variado: "A regulação contempla uma gama mais ampla de atribuições, relacionadas ao desempenho de atividades econômicas e à prestação de serviços públicos, incluindo sua disciplina, fiscalização, composição de conflitos e aplicação eventual de sanções.” (MOREIRA NETO, 2003, p. 107).

Assim, temos no Brasil um conjunto de definições próprio da conjuntura temporal na qual surgiram as agências reguladoras brasileiras, apropriando-se de conceitos internacionais prévios, porém com objetivos diferenciados e um conjunto de regulamentações voltadas à busca das soluções e adaptações necessárias para o funcionamento dessas organizações no país.

\section{- Orçamento público e as agências reguladoras}

No contexto da Administração Pública, o orçamento é, em sentido amplo, o instrumento de planejamento financeiro que possibilita ao Estado desempenhar suas funções econômicas. As agências reguladoras sujeitam-se aos instrumentos de planejamento do 
CONTINGENCIAMENTO ORÇAMENTÁRIO E AUTONOMIA NAS AGÊNCIAS

REGULADORAS: o caso da Agência Nacional de Telecomunicações

orçamento público. De acordo com Di Pietro (2007), no que concerne às finanças públicas das entidades integrantes da Administração Pública indireta, a CF de 1988 prevê a sujeição aos limites globais e condições para as operações de crédito externo e interno, estabelecidos pelo Senado Federal e aplicáveis às autarquias e demais entidades controladas pelo Poder Público. $\mathrm{O}$ art. $165^{\circ}, \S 5^{\circ}$, dispõe que o orçamento das autarquias integra o do ente estatal criador, prevendo sua inclusão na Lei Orçamentária Anual (LOA). Assim, as agências reguladoras estão sujeitas às mesmas regras da pessoa jurídica de direito público que as criaram, sendo abrangidas pelo Plano Plurianual (PPA), a Lei de Diretrizes Orçamentárias (LDO) e a Lei Orçamentária Anual (LOA).

O PPA 2012-2015, denominado Plano Mais Brasil, estabelece as ações governamentais sob responsabilidade do Ministério das Comunicações, ao qual a ANATEL está vinculada. Ainda, as telecomunicações estão inseridas no contexto da mensagem presidencial na seção de Políticas de Infraestrutura, no Programa 2025 - Comunicações para o Desenvolvimento, a Inclusão e a Democracia. Assim, programas e ações que norteiam a atuação da ANATEL na execução orçamentária têm como balizador o objetivo definido no PPA de expandir a infraestrutura e os serviços de comunicação social eletrônica, telecomunicações e serviços postais, promovendo o acesso pela população e buscando as melhores condições de preço, cobertura e qualidade.

Na definição de Giacomoni (2012), a LDO orienta a elaboração da LOA, e além disso, deve compreender as metas e prioridades da administração pública federal, incluindo as despesas de capital e outras delas decorrentes, dispor sobre as alterações na legislação tributária e estabelecer a política de aplicação das agências financeiras oficiais de fomento, além de outros aspectos. Como reflexo direto da LDO em uma agência reguladora, destaca-se o efeito da meta de resultado primário (superávit primário), que materializa as limitações orçamentárias e financeiras, caracterizando o contingenciamento.

A LOA é o ato administrativo revestido de força legal que estabelece um conjunto de ações a serem realizadas, estimando o montante das fontes de recursos a serem arrecadados pelos órgãos e entidades públicas e fixando o montante dos recursos a serem aplicados na consecução dos seus programas de trabalho. (MOTA, 2006). 
André Nunes | Evandro Luiz Diefenbach $\mid$ Marco Antônio Santana Gomes

Kalina Maria Donato de Araujo

Segundo Mello (2008), os procedimentos financeiros nas autarquias obedecem às mesmas regras da contabilidade pública aplicáveis à administração direta do Estado. As autarquias estão sujeitas às normas gerais de direito financeiro constantes da Lei n⿳0 4.320 , de 17 de março de 1964 e são alcançadas pelas normas previstas na Lei de Responsabilidade Fiscal (LRF).

\section{- A Autonomia das agências reguladoras}

Agências reguladoras são organismos de estado que coordenam um espaço regulatório onde convivem interesses contrapostos do governo, dos agentes privados e da sociedade: o governo, visando disseminar e ampliar serviços; o usuário, demandante de serviços de qualidade a preços módicos; e, o agente privado, pautado por maximizar o retorno de seus investimentos. Em um ambiente como esse somente um órgão regulador dotado de alta qualificação técnica e acentuado nível de autonomia pode mitigar os riscos de captura. (STIGLER, 1971).

No Brasil, as agências reguladoras federais são autarquias em regime especial criadas por lei especifica para executar atividades típicas de estado. São entidades com patrimônio e receita próprios e que dispõe de autonomia de gestão, administrativa e financeira, nos termos dispostos no art. $5^{\circ}$, I, do Decreto-Lei $n^{\mathbf{0}} 200$, de 25 de fevereiro de 1967. Além disso, essas autarquias são dotadas de um conjunto de privilégios específicos que suas leis de criação lhes outorgaram, tendo em vista a consecução de seus fins, pelo que são consideradas autarquias de regime especial.

Embora não haja lei que defina genericamente regime especial, Mello (2008) afirma que a ideia subjacente é a de que tais autarquias têm mais liberdade que as demais. Segundo Barroso (2005), com a instituição desse regime jurídico especial, procurou-se demarcar um espaço de legítima discricionariedade, com predomínio de juízos técnicos sobre as valorações políticas, visando preservar as agências reguladoras de ingerências indevidas, inclusive e, sobretudo, por parte do Estado e de seus agentes.

Porém Aragão (2004, p. 33) destaca que: “[...] a independência não deve existir apenas em relação aos demais agentes e Poderes do Estado, devendo também se impor frente aos geralmente poderosos interesses econômicos regidos pelas agências reguladoras." 
CONTINGENCIAMENTO ORÇAMENTÁRIO E AUTONOMIA NAS AGÊNCIAS

REGULADORAS: o caso da Agência Nacional de Telecomunicações

Oliveira (2015) explica que a especialidade do regime das agências pode ser resumida em três aspectos: autonomia normativa, autonomia administrativa reforçada e autonomia financeira ampliada. Para Sultani (2005) somente o respeito integral a essas características são capazes de assegurar às autarquias especiais a autonomia suficiente para consecução dos seus objetivos. Caso contrário, estariam vulneráveis a ingerências externas que, por certo, comprometeria a independência de suas ações.

A autonomia administrativa das agências reguladoras é reconhecida pelo privilégio, conferido pelas leis de criação, que lhes garantem independência gerencial para contratar, contrair obrigações e adquirir direitos em nome próprio, de acordo com o ordenamento jurídico, e também pela nomeação de dirigentes pelo poder executivo para exercer mandato fixo, sem possibilidade de exoneração salvo pelo cometimento de falta grave apurada mediante processo administrativo.

A autonomia normativa decorre da previsão nas leis de criação das agências de utilização da sua capacidade técnica especializada para elaborar o arcabouço regulatório infralegal, assegurar a sua aplicação e reprimir as infrações porventura existentes. Sobre o tema, Binenbojm (2005) ressalta que o fato de as agências reguladoras possuírem uma autonomia acentuada, não desnatura a hierarquia entre a Lei e os atos administrativos. Assim, enfatiza que todos os atos provenientes da Administração Pública estão sujeitos ao princípio da legalidade.

No entanto, não é propósito deste artigo esgotar a discussão sobre todos os aspectos consagrados em lei sobre a autonomia das agências reguladoras. $\mathrm{O}$ foco aqui recai exclusivamente sob o que se refere a autonomia financeira, entendida como a prerrogativa das agências reguladoras de arrecadar recursos para prover a sua sustentação por meio de fundo setorial, elaborar e executar a sua proposta orçamentária e financeira.

Spaventa (1949) observa que para um ente governamental ser considerado autônomo deve, além dos arcabouços organizacionais adequados, possuir características singulares, como poder determinar o seu próprio orçamento e que suas despesas obrigatórias não dependam do arbítrio de quem quer que seja, mas que derivem da lei ou dos seus próprios estatutos. 
André Nunes | Evandro Luiz Diefenbach $\mid$ Marco Antônio Santana Gomes

Kalina Maria Donato de Araujo

Sendo assim, de nada adiantaria a autonomia administrativa e normativa outorgada em lei se os recursos destinados ao custeio das despesas decorrentes das atividades de funcionamento estivessem sujeitos a prerrogativas de terceiros, no caso, de outras instâncias governamentais.

Barroso (2005) e Silveira (2004) argumentam que as agências reguladoras somente possuem condições de desempenhar adequadamente seu papel se ficarem preservadas de ingerências externas inadequadas, especialmente por parte do Poder Público, tanto no que diz respeito a suas decisões político-administrativas quanto a sua capacidade financeira.

Justen Filho (2002) enfatiza que o desempenho satisfatório das funções reservada as agências depende da disponibilidade de recursos materiais, portanto, se não forem instituídos mecanismos que assegurem a obtenção desses recursos de modo automático, a agência acabará subordinada ao processo político usual. Marques Neto (2005) afirma que a autonomia financeira é imprescindível para que o regulador tenha meios adequados para o exercício de suas atividades. Para ele, a pior captura que pode acometer uma agência é aquela de engessar suas funções por falta de meios adequados ao seu exercício, transformando-a em um simulacro.

Para Aragão (2004) a autonomia financeira é requisito essencial para que qualquer autonomia se efetive na prática. Para esse autor, a autonomia financeira é um pressuposto lógico do exercício de todas as outras autonomias estabelecidas para as agências reguladoras.

Nesse sentido a Organização para a Cooperação e Desenvolvimento Econômico (OCDE, 2008, p. 240) recomenda que:

$$
\begin{aligned}
& \text { As agências reguladoras precisam de um orçamento claramente } \\
& \text { definido para dar suporte à estabilidade e autonomia regulatórias, } \\
& \text { e que, idealmente, esteja segregado do resto do orçamento do go- } \\
& \text { verno para que não haja capacidade ou incentivo do governo para } \\
& \text { usá-lo para outros fins, ou de segurá-lo. }
\end{aligned}
$$

Reforçando a necessidade das agências disporem de recursos próprios, apartados do caixa do Governo Central, o argumento de Justen Filho (2002) é que a instituição de taxas em favor das entidades autárquicas constitui um mecanismo para assegurar a captação pela agência de recursos para sua manutenção que assegurariam a sua autonomia em face de outras instituições estatais e privadas. Da 
CONTINGENCIAMENTO ORÇAMENTÁRIO E AUTONOMIA NAS AGÊNCIAS

REGULADORAS: o caso da Agência Nacional de Telecomunicações

mesma forma Santos (2015) aponta que essa independência seria assegurada, a princípio, pela possibilidade de cobrança de taxas regulatórias, bem como pela aplicação de multas aos agentes do setor regulado.

Com esse fito, o legislador buscou proporcionar às autarquias especiais, além das dotações orçamentárias gerais, outras fontes de receitas próprias, por meio de recursos provenientes de fundos de arrecadação, baseados na cobrança de taxa de fiscalização e na arrecadação de multas resultantes das ações fiscalizatórias e de outras atividades econômicas remuneradas que realizar.

Mas o fato de arrecadar recursos próprios não garante que a agência vai poder dispor deles integralmente. É preciso também garantir que lhe sejam assegurados os mecanismos de autonomia orçamentária, entendida por Sultani $(2005$, p. 24) como a liberdade que a autarquia possui para elaborar a sua proposta orçamentária, considerando: "(i) as diretrizes, objetivos e metas do programa integrante do PPA pelo qual se encontra responsável; (ii) o planejamento estratégico estabelecido; (iii) as receitas previstas (dotações orçamentárias gerais e outras fontes de receitas próprias), e (iv) as despesas estimadas."

Deduz-se, então, que a autonomia em questão tem por finalidade dotar as agências de liberdade para definir e executar, de acordo com suas atribuições legais, o planejamento financeiro e orçamentário destinado ao cumprimento da missão que lhe foi outorgada.

\section{- O orçamento na ANATEL, o planejamento e o processo orçamentário}

No âmbito da reforma administrativa do estado brasileiro, ocorrida na década de 1990, a redação dada pela Emenda Constitucional no 8/1995, o art. $21^{\circ}$, XI, a CF do Brasil passou a prever a criação de um órgão regulador dos serviços de telecomunicações. Com base nesse comando constitucional, a ANATEL foi a primeira agência reguladora a ser instalada no Brasil, em 5 de novembro de 1997, por meio da Lei no 9.472, a chamada Lei Geral de Telecomunicações (LGT).

O art. $8^{\circ}$ da LGT define a criação da ANATEL como entidade integrante da Administração Pública Federal indireta, submetida a regime autárquico especial e vinculada ao Ministério das Comu- 
André Nunes $\mid$ Evandro Luiz Diefenbach $\mid$ Marco Antônio Santana Gomes

Kalina Maria Donato de Araujo

nicações, com a função de órgão regulador das telecomunicações. No $\S 2^{\circ}$ explicita que a natureza de autarquia especial conferida à Agência é caracterizada por independência administrativa, ausência de subordinação hierárquica, mandato fixo e estabilidade de seus dirigentes e autonomia financeira.

Cabe à ANATEL, com base nesse normativo, adotar as medidas necessárias para o atendimento do interesse público e para o desenvolvimento das telecomunicações brasileiras, atuando com independência, imparcialidade, legalidade, impessoalidade e publicidade. No rol de atribuições dessa agência, destacam-se as dispostas no art. $19^{\circ}$ da LGT, especialmente as dos incisos XXI, qual seja, arrecadar e aplicar suas receitas e XXVI, formular ao Ministério das Comunicações proposta de orçamento.

Para compor a LOA a ANATEL elabora anualmente a sua proposta orçamentária com base no planejamento para o exercício subsequente. Para tanto, considera as diretrizes, metas e objetivos previstos no PPA e no planejamento estratégico, além de observar a LDO. Dessa proposta constam a estimativa de despesa para cada uma das ações integrantes do programa e a expectativa de receita, inclusive fontes de receitas próprias.

Uma vez preparada a proposta orçamentária, essa é encaminhada para o Ministério das Comunicações, instância governamental a qual a autarquia encontra-se vinculada, conforme atribuição disposta no inciso XXVI do artigo no 19 da LGT. A proposta orçamentária do Ministério das Comunicações, juntamente com a de suas entidades vinculadas, é, então, enviada ao Ministério do Planejamento, Desenvolvimento e Gestão (MPOG), onde compete à Secretaria de Orçamento e Finanças (SOF) coordenar, consolidar e supervisionar a elaboração da LDO e da LOA.

Esse fluxo revela-se, em tese, condizente com o exposto anteriormente sobre a autonomia orçamentária das agências reguladoras, posto que permitiria a ANATEL elaborar a sua peça orçamentária, de acordo com o seu planejamento de atividades e limitada apenas pela previsão de receitas decorrentes do Fundo de Fiscalização dos Serviços de Telecomunicações (FISTEL), criado especificamente para servir de fonte de financiamento para essa Agência.

Mas, embora não haja qualquer normativo que dê suporte a outras instâncias governamentais fazerem propositura de alterações 
CONTINGENCIAMENTO ORÇAMENTÁRIO E AUTONOMIA NAS AGÊNCIAS

REGULADORAS: o caso da Agência Nacional de Telecomunicações

nos orçamentos definidos pelas entidades autárquicas em regime especial, na prática tal falta de competência é ignorada. Operacionalmente, quando do encaminhamento das propostas orçamentárias para compor a LOA, os valores limites já foram estabelecidos pela Administração Central, em regra, desconsiderando o planejamento e a estimativa de arrecadação própria da Agência.

Dessa forma, independentemente do planejamento elaborado pela autarquia, e mesmo que a previsão de receita supere as despesas estimadas, o que geralmente ocorre, há sempre uma intervenção da Administração Central no conteúdo da proposta apresentada, efetuando, de plano, alguns cortes de despesas. Os limites de redução propostos, além de não encontrarem qualquer amparo legal ou infralegal, não possuem correlação com a previsão de receita, sendo invariavelmente inferiores a essa.

A Tabela 1 possibilita confrontar os valores referentes aos recursos próprios arrecadados pela ANATEL com os valores que lhe foram atribuídos a título de dotação orçamentária desde a sua criação.

Tabela 1 - Arrecadação própria e orçamento da ANATEL

\begin{tabular}{c|c|c|c}
\hline ANO & $\begin{array}{c}\text { Arrecadado FISTEL } \\
(\mathrm{R} \$)\end{array}$ & $\begin{array}{c}\text { Dotação Autorizada na LOA } \\
(\mathrm{R} \$)\end{array}$ & Diferença (R\$) \\
\hline 1997 & $39.519 .785,00$ & $119.055 .735,00$ & $-79.535 .950,00$ \\
\hline 1998 & $485.435 .993,70$ & $336.563 .179,00$ & $148.872 .814,70$ \\
\hline 1999 & $1.221 .315 .767,87$ & $276.056 .341,00$ & $945.259 .426,87$ \\
\hline 2000 & $2.278 .392 .283,13$ & $355.379 .950,00$ & $1.923 .012 .333,13$ \\
\hline 2001 & $4.430 .288 .813,08$ & $518.391 .800,00$ & $3.911 .897 .013,08$ \\
\hline 2002 & $2.693 .774 .647,71$ & $556.488 .259,00$ & $2.137 .286 .388,71$ \\
\hline 2003 & $1.287 .805 .745,90$ & $339.832 .296,00$ & $947.973 .449,90$ \\
\hline 2004 & $2.018 .875 .365,50$ & $300.994 .955,00$ & $1.717 .880 .410,50$ \\
\hline 2005 & $2.098 .321 .840,73$ & $473.193 .158,00$ & $1.625 .128 .682,73$ \\
\hline 2006 & $2.097 .647 .256,27$ & $248.676 .575,00$ & $1.848 .970 .681,27$ \\
\hline 2007 & $3.083 .885 .885,05$ & $356.365 .318,00$ & $2.727 .520 .567,05$ \\
\hline 2008 & $6.416 .860 .768,75$ & $381.565 .082,00$ & $6.035 .295 .686,75$ \\
\hline 2009 & $4.909 .916 .388,91$ & $397.651 .833,00$ & $4.512 .264 .555,91$ \\
\hline 2010 & $3.431 .253 .198,90$ & $484.371 .790,00$ & $2.946 .881 .408,90$ \\
\hline 2011 & $7.268 .248 .894,39$ & $497.115 .291,00$ & $6.771 .133 .603,39$ \\
\hline 2012 & $4.918 .547 .729,07$ & $498.559 .737,00$ & $4.419 .987 .992,07$ \\
\hline 2013 & $4.913 .831 .522,13$ & $534.179 .185,00$ & $4.379 .652 .337,13$ \\
\hline 2014 & $8.772 .071 .141,01$ & $487.428 .212,00$ & $8.284 .642 .929,01$ \\
\hline 2015 & $5.405 .411 .038,84$ & $484.408 .907,00$ & $4.921 .002 .131,84$ \\
\hline Total & $67.771 .404 .065,94$ & $7.646 .277 .603,00$ & $60.125 .126 .462,94$ \\
\hline
\end{tabular}

Fonte: Elaborada pelos autores, conforme: AGÊNCIA NACIONAL DE TELECOMUNICAÇÕES. [Relatórios de Gestão]. Relatório de Gestão anual, apresentado aos órgãos de controle interno e externo e à sociedade como prestação de contas anual a que esta unidade jurisdicionada está obrigada nos termos do parágrafo único do art. 70 da Constituição Federal. Brasília, DF, 1997-2015. Disponível em: <http:// portal.anatel.gov.br/institucional/institucional-menu/relatorio-institucional> Acesso em: 06 dez. 2016. 
André Nunes | Evandro Luiz Diefenbach $\mid$ Marco Antônio Santana Gomes

Kalina Maria Donato de Araujo

Como se pode observar, nesse período a ANATEL arrecadou mais de $\mathrm{R} \$ 67$ bilhões, teve dotação orçamentária de R \$ 7,64 bilhões, que corresponde a $11,2 \%$, e deixou nos cofres públicos mais de R $\$ 60$ bilhões.

Verifica-se, assim, que não se trata de uma atuação da Administração central como coordenadora, consolidadora e supervisora, como seria de se esperar. Ela acaba atuando diretamente na confecção da proposta, deliberando, inclusive, sobre o seu texto final. Portanto, a proposta orçamentária encaminhada ao Congresso Nacional acaba sendo elaborada pela Administração Central, e não pela autarquia, o que fere a autonomia concedida à Agência pelo legislador.

\section{- A receita própria vinculada e o contingenciamento}

Destinado a prover recursos para cobrir despesas com a execução de fiscalização de serviços de telecomunicações, o desenvolvimento de meios e o aperfeiçoamento da técnica necessária, o FISTEL foi criado pela Lei ${ }^{\circ} 5.070$, de 17 de março de 1966. Esse fundo, gerido pela ANATEL, tem como base da sua composição a Taxa de Fiscalização de Instalação (TFI) e a Taxa de Fiscalização de Funcionamento (TFF), as multas aplicadas em desfavor das prestadoras de serviços de telecomunicações em decorrência de descumprimento alguns dispositivos da LGT, os recursos decorrentes da outorga de serviços de telecomunicações, os juros de aplicações financeiras e outras atividades remuneradas que a Agência realizar.

Nas palavras de Justen Filho (2002), a instituição de taxas em favor das entidades autárquicas constitui um mecanismo para assegurar a captação pela Agência de recursos para sua manutenção. Mais do que isso, assegura-se a autonomia financeiro-orçamentária que impede a redução da autonomia da agência em face de outras instituições estatais ou de empresas privadas.

A instituição da taxa de fiscalização está prevista no art. $145^{\circ}$, inciso II, da CF do Brasil:

Art. 145. A União, os Estados, o Distrito Federal e os Municípios poderão instituir os seguintes tributos:

$[\ldots]$

II - taxas, em razão do exercício do poder de polícia ou pela utilização, efetiva ou potencial, de serviços públicos específicos e 
CONTINGENCIAMENTO ORÇAMENTÁRIO E AUTONOMIA NAS AGÊNCIAS

REGULADORAS: o caso da Agência Nacional de Telecomunicações

divisíveis, prestados ao contribuinte ou postos a sua disposição. (BRASIL, 1988).

Essa taxa possui caráter vinculado, por ser devida em decorrência de uma prestação estatal específica em favor do contribuinte, e caráter retributivo, por se basear no Princípio do Custo x Benefício. Além da previsão constitucional, a instituição de taxa também é prevista pelo Código Tributário Nacional (CTN) de 1966:

Art. 77. As taxas cobradas pela União, pelos Estados, pelo Distrito Federal ou pelos Municípios, no âmbito de suas respectivas atribuições, têm como fato gerador o exercício regular do poder de polícia, ou a utilização, efetiva ou potencial, de serviço público específico e divisível, prestado ao contribuinte ou posto à sua disposição. (BRASIL, 1966).

As taxas encontram-se vinculadas a uma contraprestação específica do Estado. Trata-se de fonte de financiamento atrelada a determinada finalidade, que pode ser o exercício do Poder de Polícia ou a utilização, efetiva ou potencial, de determinado serviço.

Portanto, essa espécie de tributo está estritamente vinculada a uma contraprestação específica do Estado, sendo inadmissível a aplicação dos recursos provenientes das taxas de fiscalização atribuídas às autarquias especiais para outras atividades, que não aquelas relacionadas à sua missão finalística. Assim, a sua utilização para objetivos diversos representa um desvio da finalidade compensatória da taxa.

Os valores apresentados na Tabela 2 demonstram que, desde a sua criação em 1997, a ANATEL auferiu receitas próprias da ordem de R\$ 67,77 bilhões, ante a uma estimativa de arrecadação de $\mathrm{R} \$ 63,83$ bilhões, o que resultou em uma diferença positiva da ordem de $\mathrm{R} \$ 3,93$ bilhões.

Tabela 2 - Arrecadação própria da ANATEL

\begin{tabular}{cr|r|r|r}
\hline $\begin{array}{c}\text { ANOI } \\
\text { RECEITA }\end{array}$ & \multicolumn{1}{c}{ Previsto (R\$) } & \multicolumn{1}{c}{ Arrecadado (R\$) } & \multicolumn{1}{c}{ Diferença (R\$) } & \multicolumn{1}{c}{ Acumulado (R\$) } \\
\hline 1997 & 0,00 & $39.519 .785,00$ & $39.519 .785,00$ & $39.519 .785,00$ \\
\hline 1998 & 0,00 & $485.435 .993,70$ & $485.435 .993,70$ & $524.955 .778,70$ \\
\hline 1999 & 0,00 & $1.221 .315 .767,87$ & $1.221 .315 .767,87$ & $1.746 .271 .546,57$ \\
\hline 2000 & $2.341 .926 .873,00$ & $2.278 .392 .283,13$ & $-63.534 .589,87$ & $4.024 .663 .829,70$ \\
\hline 2001 & $7.915 .917 .409,00$ & $4.430 .288 .813,08$ & $-3.485 .628 .595,92$ & $8.454 .952 .642,78$ \\
\hline 2002 & $5.140 .704 .769,00$ & $2.693 .774 .647,71$ & $-2.446 .930 .121,29$ & $11.148 .727 .290,49$ \\
\hline 2003 & $866.787 .184,00$ & $1.287 .805 .745,90$ & $421.018 .561,90$ & $12.436 .533 .036,39$ \\
\hline
\end{tabular}


André Nunes | Evandro Luiz Diefenbach| Marco Antônio Santana Gomes Kalina Maria Donato de Araujo

\begin{tabular}{r|r|r|r|c}
\hline 2004 & $975.961 .000,00$ & $2.018 .875 .365,50$ & $1.042 .914 .365,50$ & $14.455 .408 .401,89$ \\
\hline 2005 & $2.275 .097 .516,00$ & $2.098 .321 .840,73$ & $-176.775 .675,27$ & $16.553 .730 .242,62$ \\
\hline 2006 & $2.349 .072 .091,00$ & $2.097 .647 .256,27$ & $-251.424 .834,73$ & $18.651 .377 .498,89$ \\
\hline 2007 & $2.161 .825 .630,00$ & $3.083 .885 .885,05$ & $922.060 .255,05$ & $21.735 .263 .383,94$ \\
\hline 2008 & $2.593 .259 .481,00$ & $6.416 .860 .768,75$ & $3.823 .601 .287,75$ & $28.152 .124 .152,69$ \\
\hline 2009 & $3.801 .764 .839,00$ & $4.909 .916 .388,91$ & $1.108 .151 .549,91$ & $33.062 .040 .541,60$ \\
\hline 2010 & $4.138 .710 .762,00$ & $3.431 .253 .198,90$ & $-707.457 .563,10$ & $36.493 .293 .740,50$ \\
\hline 2011 & $3.287 .628 .747,00$ & $7.268 .248 .894,39$ & $3.980 .620 .147,39$ & $43.761 .542 .634,89$ \\
\hline 2012 & $5.554 .611 .342,00$ & $4.918 .547 .729,07$ & $-636.063 .612,93$ & $48.680 .090 .363,96$ \\
\hline 2013 & $6.458 .641 .233,00$ & $4.913 .831 .522,13$ & $-1.544 .809 .710,87$ & $53.593 .921 .886,09$ \\
\hline 2014 & $8.632 .672 .029,00$ & $8.772 .071 .141,01$ & $139.399 .112,01$ & $62.365 .993 .027,10$ \\
\hline 2015 & $5.339 .709 .308,00$ & $5.405 .411 .038,84$ & $65.701 .730,84$ & $67.771 .404 .065,94$ \\
\hline Total & $63.834 .290 .213,00$ & $67.771 .404 .065,94$ & $3.937 .113 .852,94$ & $*$ \\
Geral & &
\end{tabular}

Fonte: Elaborada pelos autores, conforme Relatórios anuais de gestão da ANATEL (1997-2015).

Inicialmente, comparando a previsão frente ao montante de recursos efetivamente arrecadado, o excedente de $6,17 \%$ acima do previsto pode parecer um fator positivo, no entanto, tanto essa quanto a situação inversa não são desejáveis, uma vez que, conforme enuncia Mota (2006), o Princípio do Equilíbrio estabelece que o total da despesa orçamentária não pode ultrapassar o da receita prevista para cada exercício financeiro. Logo, o excesso de previsão levaria, em regra, à sobre estimativa da despesa, assim como a insuficiência ocasionaria a subestimativa da despesa, resultados que podem vir a comprometer a atuação do regulador.

Há de se perceber que o montante da arrecadação anual apresenta variação significativa. Isto se deve principalmente, segundo se pode levantar nos relatórios de gestão da ANATEL que serviram como base para elaboração do Gráfico 1, a ocorrência de ciclos com maior arrecadação de recursos provenientes de outorga de serviços, notadamente nos anos de 2001, 2008, 2011 e 2014. 
CONTINGENCIAMENTO ORÇAMENTÁRIO E AUTONOMIA NAS AGÊNCIAS REGULADORAS: o caso da Agência Nacional de Telecomunicações

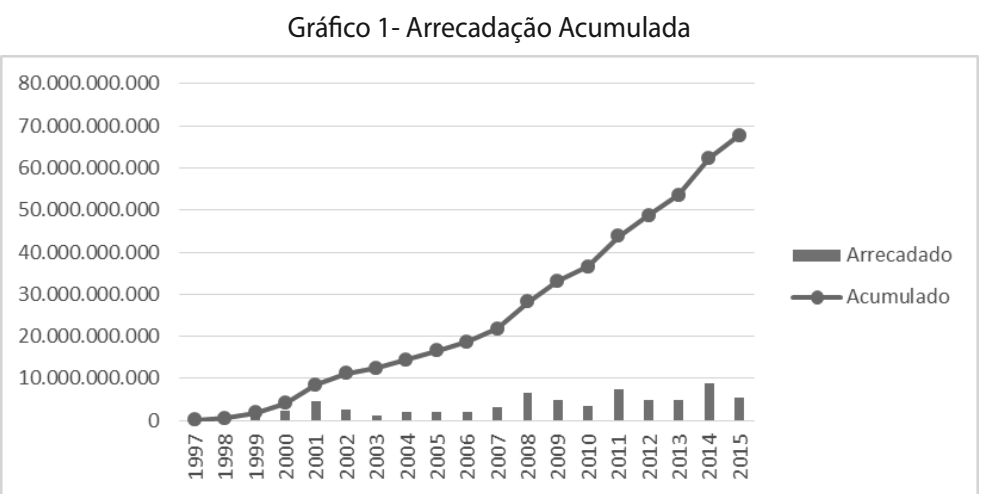

Fonte: Elaborado pelos autores, conforme Relatórios anuais de gestão da ANATEL (1997-2015).

A preocupação com a arrecadação da receita, inclusive com a precisão de sua previsão, no âmbito deste trabalho, se dá no sentido de demonstrar que o superávit primário que vem sendo alcançado ao longo dos últimos anos está se realizando via contingenciamento das receitas próprias da ANATEL estabelecidas Lei n⿳⺈ 5.070/1966 em detrimento das necessidades da Agência e do setor de telecomunicações brasileiro e, consequentemente, dos usuários dos serviços.

Considerando que a proposta orçamentária elaborada por uma autarquia tem por base uma estimativa de despesa alicerçada nas ações previstas em seu planejamento estratégico, pode-se concluir pela existência de uma compatibilidade entre os recursos a serem arrecadados e as necessidades da instituição, de modo a permitir a elaboração de um planejamento destinado à arrecadação de uma receita compatível com os gastos.

Mesmo após aprovada a proposta orçamentária em montante significativamente inferior àquele desejado e proposto pela autarquia, resultado do processo já explicitado anteriormente, ainda são efetuados contingenciamentos ao longo do exercício, conforme previsto na própria LDO, que dispõe sobre a limitação orçamentária e financeira.

O contingenciamento é dado como uma necessidade diante da situação fiscal do Brasil, onde o resultado nominal das contas públicas dos últimos anos tem apresentado situação deficitária devido ao grau de endividamento e à quantidade de juros pagos pelos títulos da dívida pública. No entanto, a receita das agências reguladoras, 
especificamente, da ANATEL, objeto de estudo deste trabalho, são receitas próprias vinculadas por lei e destinadas a garantir a autonomia financeira e orçamentária das entidades e não deveriam fazer parte do esforço fiscal da União, pelo simples motivo de não serem receitas da União.

A Tabela 3 mostra os números principais do orçamento da ANATEL desde a sua criação. Nela pode-se perceber que em 19 anos de existência da ANATEL, somente no primeiro, não houve contingenciamento orçamentário, provavelmente por algum motivo ligado ao início das suas atividades.

Tabela 3 - LOA, empenho e contingenciamento

\begin{tabular}{|c|c|c|c|}
\hline ANO & LOA - Dotação Autorizada (R\$) & $\begin{array}{c}\text { Dotação Liberada para } \\
\text { Empenho (R\$) }\end{array}$ & $\begin{array}{c}\text { Contingenciamento } \\
(\mathrm{R} \$)\end{array}$ \\
\hline 1997 & $119.055 .735,00$ & $119.055 .735,00$ & 0,00 \\
\hline 1998 & $336.563 .179,00$ & $209.059 .117,00$ & $127.504 .062,00$ \\
\hline 1999 & $276.056 .341,00$ & $261.567 .710,00$ & $14.488 .631,00$ \\
\hline 2000 & $355.379 .950,00$ & $341.172 .433,00$ & $14.207 .517,00$ \\
\hline 2001 & $518.391 .800,00$ & $309.091 .800,00$ & $209.300 .000,00$ \\
\hline 2002 & $556.488 .259,00$ & $318.931 .688,00$ & $237.556 .571,00$ \\
\hline 2003 & $339.832 .296,00$ & $241.989 .591,41$ & $97.842 .704,59$ \\
\hline 2004 & $300.994 .955,00$ & $280.224 .770,00$ & $20.770 .185,00$ \\
\hline 2005 & $473.193 .158,00$ & $256.596 .684,00$ & $216.596 .474,00$ \\
\hline 2006 & $248.676 .575,00$ & $239.630 .292,00$ & $9.046 .283,00$ \\
\hline 2007 & $356.365 .318,00$ & $280.855 .151,00$ & $75.510 .167,00$ \\
\hline 2008 & $381.565 .082,00$ & $327.133 .066,00$ & $54.432 .016,00$ \\
\hline 2009 & $397.651 .833,00$ & $335.558 .214,00$ & $62.093 .619,00$ \\
\hline 2010 & $484.371 .790,00$ & $390.297 .649,23$ & $94.074 .140,77$ \\
\hline 2011 & $497.115 .291,00$ & $401.154 .155,10$ & $95.961 .135,90$ \\
\hline 2012 & $498.559 .737,00$ & $443.019 .882,22$ & $55.539 .854,78$ \\
\hline 2013 & $534.179 .185,00$ & $475.899 .922,77$ & $58.279 .262,23$ \\
\hline 2014 & $487.428 .212,00$ & $459.446 .916,32$ & $27.981 .295,68$ \\
\hline 2015 & $484.408 .907,00$ & $460.837 .855,00$ & $23.571 .052,00$ \\
\hline Total & $7.646 .277 .603,00$ & $6.151 .522 .632,05$ & $1.494 .754 .970,95$ \\
\hline Média & $402.435 .663,32$ & $323.764 .349,06$ & $78.671 .314,26$ \\
\hline
\end{tabular}

No período estudado, a ANATEL teve seu orçamento contingenciado na ordem de $\mathrm{R} \$ 1,49$ bilhão, sendo a média dos contingenciamentos anuais da ordem de $\mathrm{R} \$ 78,6$ milhões. Estes valores representam $19 \%$ da dotação autorizada na LOA para a ANATEL 
CONTINGENCIAMENTO ORÇAMENTÁRIO E AUTONOMIA NAS AGÊNCIAS

REGULADORAS: o caso da Agência Nacional de Telecomunicações

no período. Ressalva-se que a média não espelha os valores anuais, visto que, desconsiderando o ano atípico de 1997, os valores encontrados variaram de um percentual de $4 \%$ no ano 2000 até $46 \%$ em 2005. Tal fato contraria flagrantemente o disposto no art. 15 da LGT, que assegura que: "A fixação das dotações orçamentárias da Agência na Lei de Orçamento Anual e sua programação orçamentária e financeira de execução não sofrerão limites nos seus valores para movimentação e empenho." (BRASIL, 1997b).

Porém, observando os dados da Tabela 3 e no Gráfico 2 percebe-se uma aproximação e possível correlação dos valores autorizados na LOA com os efetivamente liberados para empenho a partir do ano de 2006. Isto remete a uma avaliação mais minuciosa de suas possíveis causas.

Gráfico 2 - LOA, empenho e contingenciamento

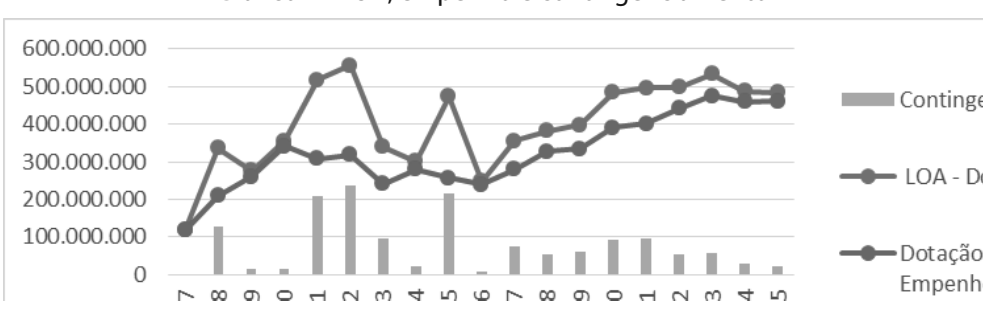

Fonte: Elaborado pelos autores, conforme Relatórios anuais de gestão da ANATEL (1997-2015).

Posto que o Governo Central, como já demonstrado, possui mecanismos para limitar o teto orçamentário da Agência sem considerar o planejamento estratégico e o volume de recursos por ela arrecadado. Cabe examinar, a existência de um possível piso orçamentário surgido da interação da Agência com o Governo Central.

Examinando os componentes da peça orçamentária da ANATEL, percebe-se que basicamente se destinam ao pagamento de despesas relativas a três rubricas: Pessoal e Encargos; Outras Despesas Correntes (ODC); e Investimentos. Dessas, a rubrica Pessoal e Encargos tem características mais rígidas no uso de seus recursos, pois se destina exclusivamente ao pagamento da folha de pessoal e seus encargos sociais, cuja ocorrência é perene e bastante previsível. As demais permitem uma maior discricionariedade da Agência no emprego de seus recursos, pois possuem características de maior sazonalidade e menor previsibilidade em face do seu planejamento e das atividades desenvolvidas. 
André Nunes | Evandro Luiz Diefenbach $\mid$ Marco Antônio Santana Gomes Kalina Maria Donato de Araujo

O Gráfico 3 mostra a evolução do orçamento da ANATEL em função de suas rubricas de despesa.

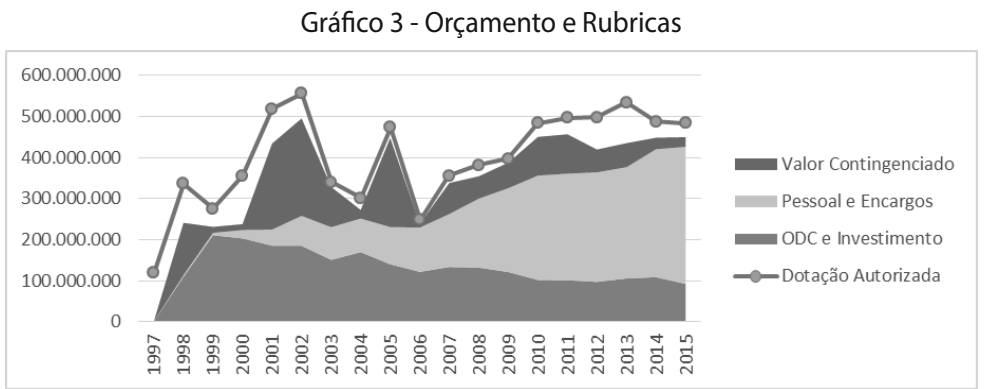

Fonte: Elaborado pelos autores, conforme Relatórios anuais de gestão da ANATEL (1997-2015).

É possível perceber que há um comportamento distinto tanto do orçamento quanto da despesa da Agência no período anterior e posterior a 2006. Pelo lado do orçamento, no período anterior há uma grande oscilação na dotação autorizada, seguida pari passu por um nível de contingenciamento, que mantem os custos operacionais da Agência em patamar constante. Do lado da despesa, é perceptível que a maior fatia do gasto se destina a investimentos e ao custeio das ODC.

A partir de 2007 ocorre uma inflexão pelo lado da despesa, onde o montante destinado à rubrica Pessoal e Encargos supera $\mathrm{e}$ se distancia cada vez mais do destinado a ODC e Investimentos. Pelo que foi possível apurar, por meio dos relatórios de gestão da ANATEL, o aumento da despesa com pessoal coincide com o início da composição do quadro de servidores efetivos de carreira da Agência em substituição aos servidores cedidos por outros órgãos governamentais ou contratados temporariamente nos primeiros anos de funcionamento.

Mas, há também uma razão para a redução gradativa dos recursos destinados a rubrica ODC e Investimentos. A pressão exercida via limitação da dotação orçamentária, somada a imposição de uma fatia de contingenciamento, impõe uma redução do custo operacional da Agência que se reflete em maior proporção na redução do gasto com essa rubrica dada a maior rigidez jurídica para uso dos recursos com Pessoal e Encargos. 
CONTINGENCIAMENTO ORÇAMENTÁRIO E AUTONOMIA NAS AGÊNCIAS

REGULADORAS: o caso da Agência Nacional de Telecomunicações

Essa combinação de limitação e contingenciamento orçamentário dificulta o planejamento e a execução das atividades regulatórias da Agência, com repercussões negativas de grande impacto para o setor de telecomunicações. Dado que esse setor está intimamente associado ao desenvolvimento do país e mobiliza expressiva quantia de capital, o impacto gerado pela atividade regulatória da Agência tende a ser relativamente maior que o montante de seu orçamento.

Acrescente-se a essa combinação, ainda, o descompasso entre o montante anualmente arrecadado com o fundo vinculado, o FISTEL, e a dotação orçamentária autorizada. Isto produz uma retirada de recursos com efeito asfixiante para o investimento no setor e perverso para o usuário do serviço, que em última instância paga o incremento de preço decorrente na prestação do serviço, sem a garantia de uma atuação efetiva do órgão regulador.

Diante desse cenário, o Tribunal de Contas da União (TCU), em auditoria operacional realizada sob encomenda da Câmara dos Deputados com o objetivo de analisar a governança regulatória das agências reguladoras federais de infraestrutura, reconhece que: "A criação de mecanismos/instrumentos formais que propiciem uma maior estabilidade e uma maior previsibilidade na descentralização de recursos para as agências reguladoras traria benefícios à governança da atividade regulatória.” (BRASIL, 2011).

Assim, em seu Acórdão n 2261/2011 o TCU recomenda a:

9.8.4. criação de mecanismos/instrumentos formais que propiciem maior estabilidade e maior previsibilidade na descentralização de recursos para as agências;

9.8.5. caracterização das agências em órgãos setoriais, desvinculando seus orçamentos dos respectivos ministérios vinculadores; (BRASIL, 2011).

\section{CONCLUSÃO}

As agências reguladoras trazem em si condições de independência de ação e liberdade administrativa que as tornam um instrumento flexível e eficiente de ação. A gestão mais dinâmica, econômica e transparente faz com que sejam minimizadas as questões burocráticas que normalmente retardam as decisões do Estado quando do cumprimento de sua missão. 
André Nunes | Evandro Luiz Diefenbach $\mid$ Marco Antônio Santana Gomes

Kalina Maria Donato de Araujo

A respeito das características atribuídas a essas autarquias especiais, temos que somente em conjunto as mesmas são capazes de lhes assegurar uma autonomia reforçada. A autonomia técnica não prescinde da autonomia financeira e orçamentária, sendo essa fundamental para que as entidades possam agir sem a ingerência da Administração Central.

Nesse sentido, foi conferida às agências reguladoras a competência para determinar o seu orçamento, devendo ser observados, no entanto, a metodologia de planejamento orçamentário estabelecida pela $\mathrm{CF}$ e o Princípio da Unidade Orçamentária. Por outro lado, tais entidades contam com fontes próprias de recursos, dentre as quais pode ser destacada a taxa de fiscalização, destinados ao financiamento de suas atividades e capazes de lhes assegurar uma independência de atuação.

Todavia, a autonomia financeira e orçamentária atribuída por lei às agências reguladoras tem sido, na prática, desrespeitada pela Administração Central, pelo menos no que se refere a ANATEL. As evidências coletadas e analisadas, no âmbito deste trabalho, trazem a convicção de que a Administração Central interfere na elaboração da proposta orçamentária da ANATEL e administra a maior parte dos recursos por ela arrecadados, transformando-os em poupança para fins de equalização das contas públicas e redução do déficit primário da Administração Central. Tal fato, além de ser contrário à CF do Brasil, a diversas Leis Complementares (CTN e LRF), à Lei Geral de Telecomunicações e a recorrentes entendimentos do Supremo Tribunal Federal (STF) e do TCU, acaba por colocar em risco a principal característica dessa autarquia especial, que é a sua autonomia.

Dessa forma, torna-se imperioso evitar que as autarquias especiais sejam alcançadas pelas influências centralizadoras de padronização, uniformização e controle. Caso contrário, a sua administração se tornará tão rígida quanto a do próprio Estado, fazendo desaparecer as razões de conveniência que originaram sua instituição.

\section{REFERÊNCIAS}

AGÊNCIA NACIONAL DE TELECOMUNICAÇÕES. [Relatórios de Gestão]. Relatório de Gestão anual, apresentado aos órgãos de controle interno e externo e à sociedade como prestação de contas anual a que esta unidade jurisdicionada está obrigada nos termos do parágrafo único do art. 70 da Constituição Federal. Brasília, DF, 
CONTINGENCIAMENTO ORÇAMENTARIO E AUTONOMIA NAS AGÊNCIAS

REGULADORAS: o caso da Agência Nacional de Telecomunicações

1997-2015. Disponível em: <http://portal.anatel.gov.br/institucional/ institucional-menu/relatorio-institucional $>$ Acesso em: $06 \mathrm{dez} .2016$.

ARAGÃO, A. S. Agências reguladoras. 2. ed. Rio de Janeiro: Ed. Forense, 2004.

BARROSO, L. R. Constituição, ordem econômica e agências reguladoras. Revista Eletrônica de Direito Administrativo Econômico, Salvador, n- 1, fev. 2005. Disponível em: <http://www.direitodoestado. com/revista/REDAE-1-FEVEREIRO-2005-ROBERTO-BARROSO. pdf $>$. Acesso em: 15 out. 2016.

BINENBOJM, G. As agências reguladoras independentes e democracia no Brasil.: Revista Eletrônica de Direito Administrativo Econômico, Salvador, n. 3, ago./set./out. 2005. Disponível em: $<$ http:// www.direitodoestado.com.br>. Acesso em: 12 out. 2016.

BRASIL. Constituição da República Federativa do Brasil. Brasília, DF, 1988. Disponível em:<http://www.planalto.gov.br/ccivil_03/ constituicao/constituicaocompilado.htm>. Acesso em: 15 nov. 2016.

Lei no 5.172 , de 25 de outubro de 1966. Código Tributário Nacional. Dispõe sobre o Sistema Tributário Nacional e institui normas gerais de direito tributário aplicáveis à União, Estados e Municípios. Diário Oficial da União, Brasília, DF, 1966. Disponível em: < http://www.planalto.gov.br/ccivil_03/Leis/L5172.htm> Acesso em: 8 mai. 2017.

Lei $\mathrm{n}^{\mathbf{0}} 9.472$, de 16 de junho de 1997. Dispõe sobre a organização dos serviços de telecomunicações, a criação e funcionamento de um órgão regulador e outros aspectos institucionais, nos termos da Emenda Constitucional $n^{\circ}$ 8, de 1995. Diário Oficial da União, Brasília, DF, 1997b. Disponível em:<http://http://www. planalto.gov.br/ccivil_03/leis/L9472.htm>. Acesso em: 8 mai. 2017.

Tribunal de Conta da União. Plenário. Acórdão nº 2261 de 24 de agosto de 2011. Auditoria de natureza operacional. Governança regulatória no âmbito das agências reguladoras de infraestrutura. Oportunidades de melhoria. Determinações e recomendações, identificação de boas práticas, disseminação, comunicação. Brasília, DF, 2011. Disponível em:<http://portal2.tcu.gov.br/portal/page/portal/ TCU/comunidades/regulacao/Governan $\% \mathrm{C} 3 \% \mathrm{~A} 7 \mathrm{a}$ _regulatoria_ agencias_reguladoras.pdf $>$ Acesso em: 8 maio $201 \overline{7}$.

CUÉLLAR, L. As agências reguladoras e seu poder normativo. São Paulo: Dialética, 2001. 
DI PIETRO, M. S. Z. Direito administrativo. 20. ed. São Paulo: Atlas, 2007.

FERREIRA FILHO, M. G. Reforma do estado: o papel das agências reguladoras e fiscalizadoras. Fórum Administrativo, Belo Horizonte, n. 3, p. 253-257, maio 2001 .

GIACOMONI, J. Orçamento público. 16. ed. São Paulo: Atlas, 2012.

GROTTI, D. A. M. As agências reguladoras. Revista Eletrônica de Direito Administrativo Econômico - REDAE, Salvador, n. 6, maio/jul. 2006. Disponível em: $<$ http://www.direitodoestado.com/revista/redae6-maio-2006-dinora.pdf>. Acesso em: 16 out. 2016.

JUSTEN FILHO, M. O Direito das agências reguladoras independentes. São Paulo: Ed. Dialética, 2002.

MARQUES NETO, F. A. Agências reguladoras independentes: fundamentos e seu regime jurídico. Belo Horizonte: Fórum, 2005.

MELlO, C. A. B. Curso de direito administrativo. 25. ed. São Paulo: Editora Malheiros, 2008.

MISSE, D. G. História e sentido da criação das agências reguladoras no Brasil. In: ENCONTRO REGIONAL DA ANPUH-RIO,

14., 2010, Rio de Janeiro. Anais eletrônicos... Rio de Janeiro:

ANPUH, 2010. Disponível em: <http://www.encontro2010. rj.anpuh.org/resources/anais/8/1273241978_ARQUIVO

CriacaodasAgenciasReguladorasnoBrasil.p $\overline{\mathrm{d}} \mathrm{f}>$. Acesso em: 12 out. 2016.

MOREIRA NETO, D. F. Direito regulatório. Rio de Janeiro: Renovar, 2003.

MOTA, F. G. L. Curso básico de contabilidade pública. 2. ed. Brasília, DF, 2006.

OLIVEIRA, R. C. R. Administração pública, concessões e terceiro setor. 3. ed. São Paulo: Método, 2015.

ORGANIZAÇÃO PARA A COOPERAÇÃO E

DESENVOLVIMENTO ECONÔMICO. Relatório sobre a Reforma Regulatória: Fortalecendo a governança para o crescimento. Brasília, DF, 2008. Disponível em:<http://www.biblioteca.presidencia.gov. br/publicacoes-oficiais/catalogo/lula/ocde-2013-relatorio-sobrea-reforma-regulatoria-brasil-fortalecendo-a-governanca-para-ocrescimento/view> Acesso em: 17 ago. 2016. 
CONTINGENCIAMENTO ORÇAMENTÁRIO E AUTONOMIA NAS AGÊNCIAS REGULADORAS: o caso da Agência Nacional de Telecomunicações

SANTOS, A. P. P. A autonomia reforçada das agências reguladoras no Brasil. In: CONGRESSO NACIONAL DO CONPEDI, 24., 2015, Belo Horizonte. Anais eletrônicos... Belo Horizonte: UFMG, 2015. Disponível em:<http://www.conpedi.org.br/publicacoes/66fs1345/ ki9ipk3k/BH33enEpMFgInbiK.pdf>. Acesso em: 20 out. 2016.

SILVEIRA, E. R. A autonomia regulamentar das agências reguladoras. Itajaí, SC: Universidade do Vale do Itajai, 2004. Disponível em: $<$ http://siaibib01.univali.br/pdf/Ederson\%20Silveira.pdf $>$. Acesso em: 19 out. 2016.

SPAVENTA, S. La giustizianell' amministrazione. Torino: Giulio Einaudi Editore, 1949.

STIGLER, G. The theory of economic regulation. Bell Journal of Economics, [S. 1.], v. 2, p. 3-21, 1971.

SULTANI, L. J. M. Autonomia financeira e orçamentária das entidades autárquicas em regime especial. Rio de Janeiro: Universidade Federal do Rio de Janeiro, 2005. Disponível em: <http:/www.cvm.gov.br/ port/public/publ/ie_ufrj_cvm/Leonardo_Jose_Mattos_Sultani.pdf $>$. Acesso em: 19 out. $201 \overline{6}$. 
